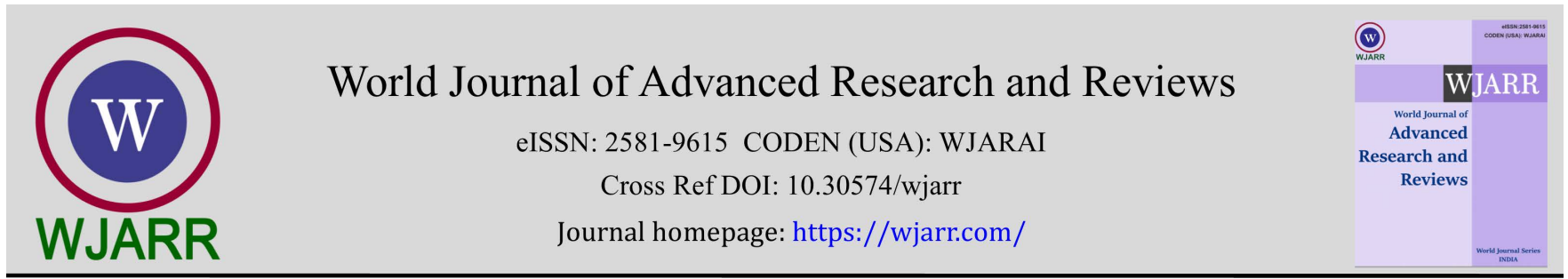

(RESEARCH ARTiCle)

Check for updates

\title{
Design of automated database system for storage and management of reports on mycotoxins contaminated agricultural products in Sub-Saharan Africa
}

\author{
Eunice C Chibudike ${ }^{1}$, Henry 0 Chibudike ${ }^{2,}{ }^{*}$, Nwaebuni E Odega ${ }^{3}$, Emeka E Njokanma ${ }^{4}$, Olubamike A \\ Adeyoju ${ }^{5}$ and Constance 0 Ngige ${ }^{1}$ \\ ${ }_{1}^{1}$ Planning, Technology Transfer and Information Management, Federal Institute of Industrial Research, Oshodi, F.I.I.R.O., \\ Lagos, Nigeria. \\ 2 Department of Chemical, Fiber and Environmental Technology, Federal Institute of Industrial Research, Oshodi, F.I.I.R.O., \\ Lagos, Nigeria. \\ ${ }^{3}$ Nigerian Upstream Petroleum Regulatory Commission (NUPRC). \\ ${ }^{4}$ Chevron Nigeria Limited. \\ ${ }^{5}$ Production, Analytical and Laboratory Management, Federal Institute of Industrial Research, Oshodi, F.I.I.R.O., Lagos, \\ Nigeria.
}

World Journal of Advanced Research and Reviews, 2022, 13(01), 763-770

Publication history: Received on 24 December 2021; revised on 29 January 2022; accepted on 30 January 2022

Article DOI: https://doi.org/10.30574/wjarr.2022.13.1.0102

\begin{abstract}
This paper discusses the idea and the design of an automated system for storage and management of mycotoxins reports for decision making. Mycotoxins are poisonous chemical compounds produced by certain fungi. Mycotoxins are fungal secondary metabolites that contaminate various feedstuffs and agricultural crops. The contamination of food by mycotoxins can occur before production, during storage, processing, transportation or marketing of the food products. High temperature, moisture content and water activity are among the factors that facilitate the production of mycotoxins in food. The five major mycotoxins produced in food and feedstuffs are Aflatoxins, ochratoxins, fumonisins, deoxynivalenol and zearalenone. In Africa, mycotoxin contamination is considered to be a major problem with implications that causes human and animal health hazards and poor economy. Aflatoxin-related hepatic diseases are reported in many African countries. Ochratoxin and fumonisin toxicity in humans and animals is widespread in Africa. The available and updated information on the incidence of mycotoxin is not collectively vivid for policy making. A complete automated system allows to monitor the statistical report of mycotoxins stored in agricultural products. This study involves analytical Service conducted on Mycotoxins such as Mold Culture and Identification and Chemical Analysis which involves microbiological Culturing; Microscopic or biochemical identification, enzyme linked Immunosorbent (ELISA), tin layer Chromatography (TLC), high Performance Liquid Chromatography (HPLC), and gas Chromatography /Mass Spectroscopy. The design and development of Mycotoxins Automated Database System (MADAS) makes provision for easy access and acknowledgment of mycotoxins in different grains, fruits, vegetables and foods in Sub-Saharan Africa. It also enhances robust data collection, management, and analysis, a secure and protected data environment, error reduction and data storage to facilitate regulatory compliance, improved maintainability, standardization, control, predictability, and traceability of data and lower costs due to automation of labor intensive tasks and elimination of redundant work.
\end{abstract}

Keywords: Sub-Saharan Africa; Health hazards; Mycotoxins automated data base system; Agricultural products

\footnotetext{
${ }^{*}$ Corresponding author: Henry 0 Chibudike

Department of Chemical, Fiber and Environmental Technology, Federal Institute of Industrial Research, Oshodi, F.I.I.R.O., Lagos, Nigeria.
}

Copyright $(2022$ Author(s) retain the copyright of this article. This article is published under the terms of the Creative Commons Attribution Liscense 4.0. 


\section{Introduction}

In Sub-Saharan Africa, work on mycotoxins covering field cases, acute exposures and chronic effects related to dietary intake is reviewed. Mycotoxins have been implicated in the etiology of diseases like kwashiorkor, marasmic kwashiorkor, hepatocellular carcinoma in humans, encephalopathy and other acute diseases in animals. Mycotoxins are poisonous chemical compounds produced by certain fungi. There are many such compounds, but only a few of them are regularly found in food and animal feedstuffs such as grains and seeds. Nevertheless, those that do occur in food have great significance in the health of humans and livestock. Since they are produced by fungi, mycotoxins are associated with diseased or moldy crops, although the visible mold contamination can be superficial. The effects of some foodborne mycotoxins are acute, symptoms of severe illness appearing very quickly. Other mycotoxins occurring in food have longer term chronic or cumulative effects on health, including the induction of cancers and immune deficiency. Information about food-borne mycotoxins is far from complete, but enough is known to identify them as a serious problem in many parts of the world, causing significant economic losses. The economic and health hazards of mycotoxin contamination in crops and food products present a huge challenge, especially in Sub-Saharan Africa, where there is limited data to ascertain the degree of harm caused by these toxins. Tackling this problem needs a multi-factorial approach. A workable strategy would be the systematic development of centers of research expertise, and building research capacities aimed at establishing a database on mycotoxins found in different grains and seeds at each given time and health-related risks caused by mycotoxins. Growing the interest of the African scientific community towards increasing the research output in the region is imperative. To this end, building an automated system on mycotoxicology is a good starting point. This will enable a better collation of data which will aid decision making. This research work will also aid the access and acknowledgment of mycotoxins reports of agricultural products in Sub-Saharan Africa. To aid policy makers in having an overview of mycotoxin reports of agricultural products in Sub-Saharan Africa. This research work will be relevant to research officers especially those in the area of mycotoxins and related research topics to have quick access to referencing data and to make comparisons as desired for better results. It will as well aid interaction between research scientists and farmers for updates. This will enable governments to make adequate policies that will help to improve and secure human and animal health.

\section{Methodology}

\subsection{Materials}

This study adopts a case study of some FIIRO scientists in Food, Biotechnology and CEFT departments. Verbal interview was conducted randomly to ascertain some facts about Mycotoxins. The following material were involved: Paper, pen, computer system, flash, and printer.

\subsection{Methods}

The analytical services used in testing for mycotoxins and the methods used are presented in tables and figure below. This gave us the insight in the designing and development of the database. The system will be able to display the services carried out and also the methods used for each agricultural product. Figure 1 shows the flow of the method used.

Table 1 Examples of Analytical Service on Mycotoxins

\begin{tabular}{|l|l|}
\hline Services & Method \\
\hline Mold Culture and Identifications. & Microbiological Culturing; Microscopic or biochemical identification test. \\
\hline Chemical Analysis & Enzyme linked Immunosorbent (ELISA). \\
& Tin layer Chromatography (TLC). \\
& High Performance Liquid Chromatography (HPLC). \\
& Gas Chromatography /Mass Spectroscopy. \\
\hline
\end{tabular}


Table 2 Examples of Food Contamination with Aflatoxins in Sub-Saharan Africa

\begin{tabular}{|c|c|c|c|c|c|c|c|c|c|}
\hline Country & Food & Year(s) & $\begin{array}{l}\text { Sample } \\
\text { source }\end{array}$ & $\begin{array}{l}\text { AF } \\
\text { types }\end{array}$ & $\mathbf{N}$ & $\begin{array}{l}\text { +ves } \\
(\%)\end{array}$ & $\begin{array}{l}\text { Range } \\
\text { (ppb) }\end{array}$ & $\begin{array}{l}\text { Mean } \\
(p p b)\end{array}$ & Ref \\
\hline \multirow[t]{2}{*}{ Nigeria } & Maize & 2001 & Preharvested & AFB1 & 103 & 18 & $3-130$ & 22 & 16 \\
\hline & $\begin{array}{l}\text { Dry roasted } \\
\text { groundnuts }\end{array}$ & (2005) & Retail & Total & 106 & 64 & $5-165$ & 25.5 & 17 \\
\hline \multirow[t]{3}{*}{ Ghana } & \multirow{2}{*}{$\begin{array}{l}\text { Kenkey } \\
\text { (fermented } \\
\text { maize) }\end{array}$} & $(2000)$ & $\begin{array}{l}\text { Processing } \\
\text { sites }\end{array}$ & Total & 15 & 53 & $2-662$ & 176 & 18 \\
\hline & & 1996 & $\begin{array}{l}\text { Processing } \\
\text { sites }\end{array}$ & Total & 12 & 100 & $0.7-313$ & 135.4 & 19 \\
\hline & $\begin{array}{l}\text { Kenkey } \\
\text { (cooked } \\
\text { fermented maize) }\end{array}$ & 1996 & $\begin{array}{l}\text { Processing } \\
\text { sites }\end{array}$ & Total & 16 & 94 & $0.7-313$ & 50.9 & 19 \\
\hline Botswana & Groundnut & 2001 & Retail Outlets & Total & 120 & 78 & $12-329$ & 118 & 20 \\
\hline
\end{tabular}

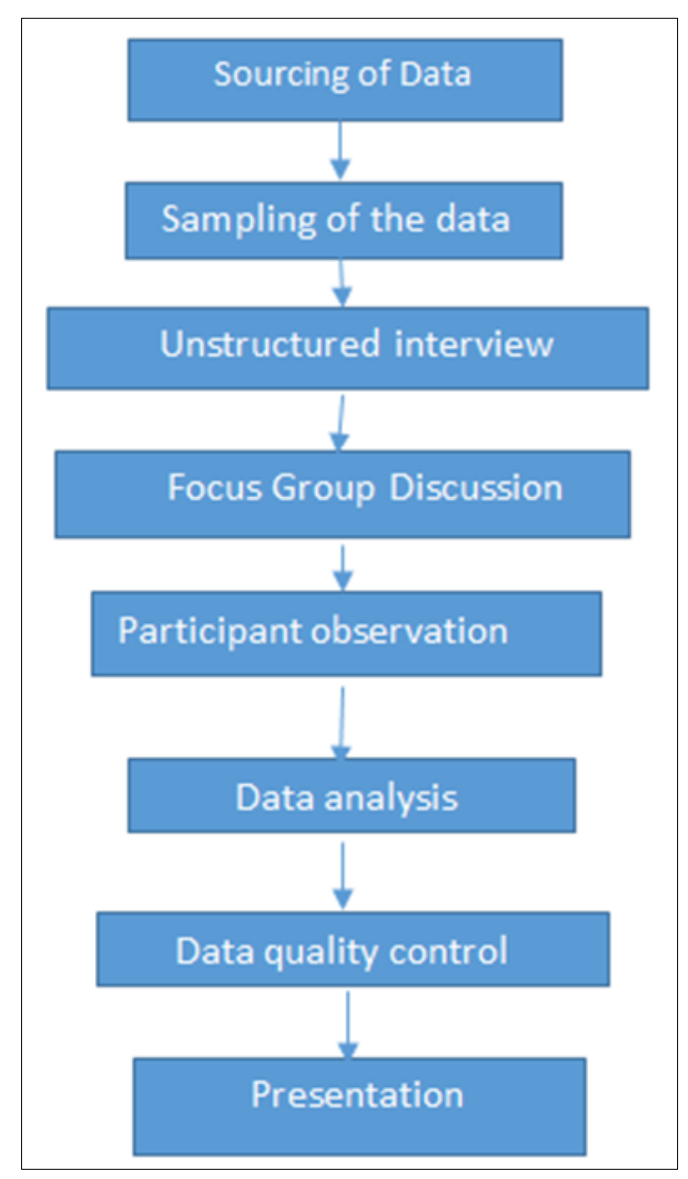

Figure 1 Flow Diagram of the Research Methods Adopted 


\section{Results and discussion}

An unstructured interview was conducted with fifteen (15) respondents in the Federal Institute of Industrial Research Oshodi, Lagos as presented in table 3. The socio-economic characteristics of the respondents and the opinions of Mycotoxins were gathered.

Table 3 research scientists (Case study)

\begin{tabular}{|l|c|c|}
\hline Department & Number & Percentage (\%) \\
\hline Biotechnology & 60 & 40 \\
\hline Food Technology & 40 & 26.7 \\
\hline CFET & 50 & 33.3 \\
\hline
\end{tabular}

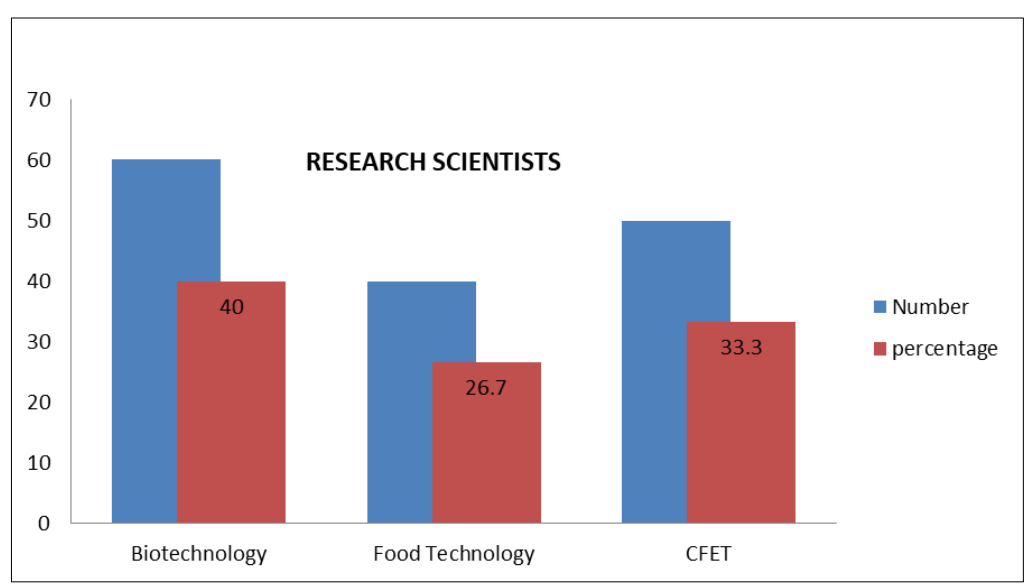

Figure 2 The Research Scientists

From Table 3, fifteen scientists responded, 6 from department of Biotechnology, 4 from Food technology department and 5 from CEFT department with 40, 26.7 and 33.3\% respectively. The socio-economic characteristics of these respondents were gathered based on UN standard, which formed Table 2.

Table 4 Socio-economic characteristics of respondents

\begin{tabular}{|l|c|c|c|}
\hline Variables & Categories & Number & Percentage (\%) \\
\hline Age & $15-25$ & 0 & 0 \\
\cline { 2 - 4 } & $25-34$ & 50 & 33.3 \\
\cline { 2 - 4 } & $34-45$ & 30 & 20 \\
\cline { 2 - 4 } & $45-54$ & 60 & 40 \\
\cline { 2 - 4 } & $54-64$ & 10 & 6.7 \\
\cline { 2 - 4 } & 65 Above & 0 & 0 \\
\hline Sex & Male & 70 & 46.7 \\
\cline { 2 - 4 } & Female & 80 & 53.3 \\
\hline \multirow{4}{*}{ Education Level } & B.Sc & 20 & 13.3 \\
\cline { 2 - 4 } & M.Sc & 60 & 40 \\
\cline { 2 - 4 } & Ph.D & 70 & 46.7 \\
\hline
\end{tabular}




\begin{tabular}{|l|c|c|c|}
\hline Marital status & Married & 90 & 60 \\
\cline { 2 - 4 } & Single & 50 & 33.3 \\
\cline { 2 - 4 } & Divorce & 0 & 0 \\
\cline { 2 - 4 } & Widow/widower & 10 & 6.7 \\
\hline
\end{tabular}

The issue of Mycotoxins in agricultural products is very vital in food and biotech industry. These caused health hazards in humans and animals. The opinions of these scientists in Table 5, formed our decision in designing an automated database system

Table 5 Mycotoxins in agricultural products

\begin{tabular}{|l|c|c|c|c|}
\hline \multicolumn{1}{|c|}{ Variables } & Yes & No & Percentage Yes & Percentage No \\
\hline Relevant Issue & 150 & 0 & 100 & 0 \\
\hline Positive Effect & 10 & 140 & 6.7 & 93.3 \\
\hline Negative Effect & 140 & 10 & 93.3 & 6.7 \\
\hline Harmful to Health & 140 & 10 & 93.3 & 6.7 \\
\hline Controlled & 50 & 100 & 33.3 & 66.7 \\
\hline Research on-going & 130 & 20 & 86.7 & 13.3 \\
\hline Involved in the research & 90 & 60 & 60 & 40 \\
\hline Need referencing data & 150 & 0 & 100 & 0 \\
\hline Internet as data source & 90 & 60 & 60 & 40 \\
\hline Database needed & 150 & 0 & 100 & 0 \\
\hline Data will quicken the solution & 150 & 0 & 100 & 0 \\
\hline
\end{tabular}

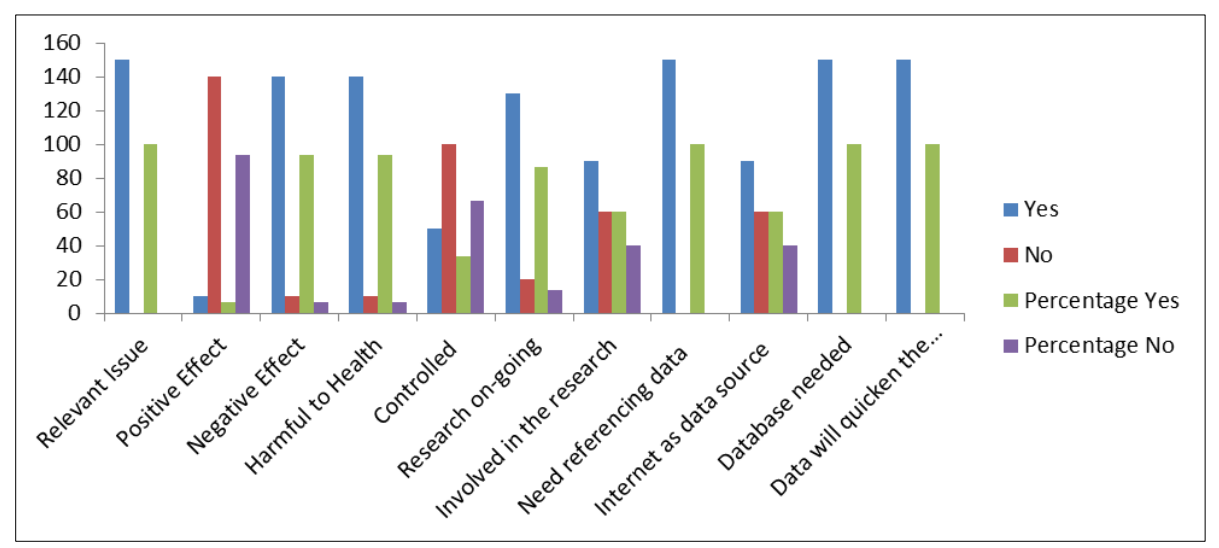

Figure 3 Mycotoxins in Agricultural products

\subsection{Mycotoxins Automated Database System (MADAS)}

A database has been developed for users to show the Mycotoxins statistical reports of agricultural products that are registered and available here in Sub-Saharan Africa.

- The languanges used are Microsoft.Net framework, C\# at front end and SQL/my SQL

- Searching the database 
In order to search the database, the following instructions must be followed:

The database is available on the website of the Federal institute of Industrial Research oshodi, (FIIRO), Lagos. http://www.mycotoxin.gov.ng.ie/biotech/crops/mycotoxinscertification/mycotoxinsdatabase/

- $\quad$ To Navigating the program: - Launch the Application

- from the investigation grid view, Click on Export to excel or pdf to print

- Add new Service/Investigation: - Launch the Application

- Click Add New- "To open the service/investigation dialog box

Table 6 The created interface of data capturing

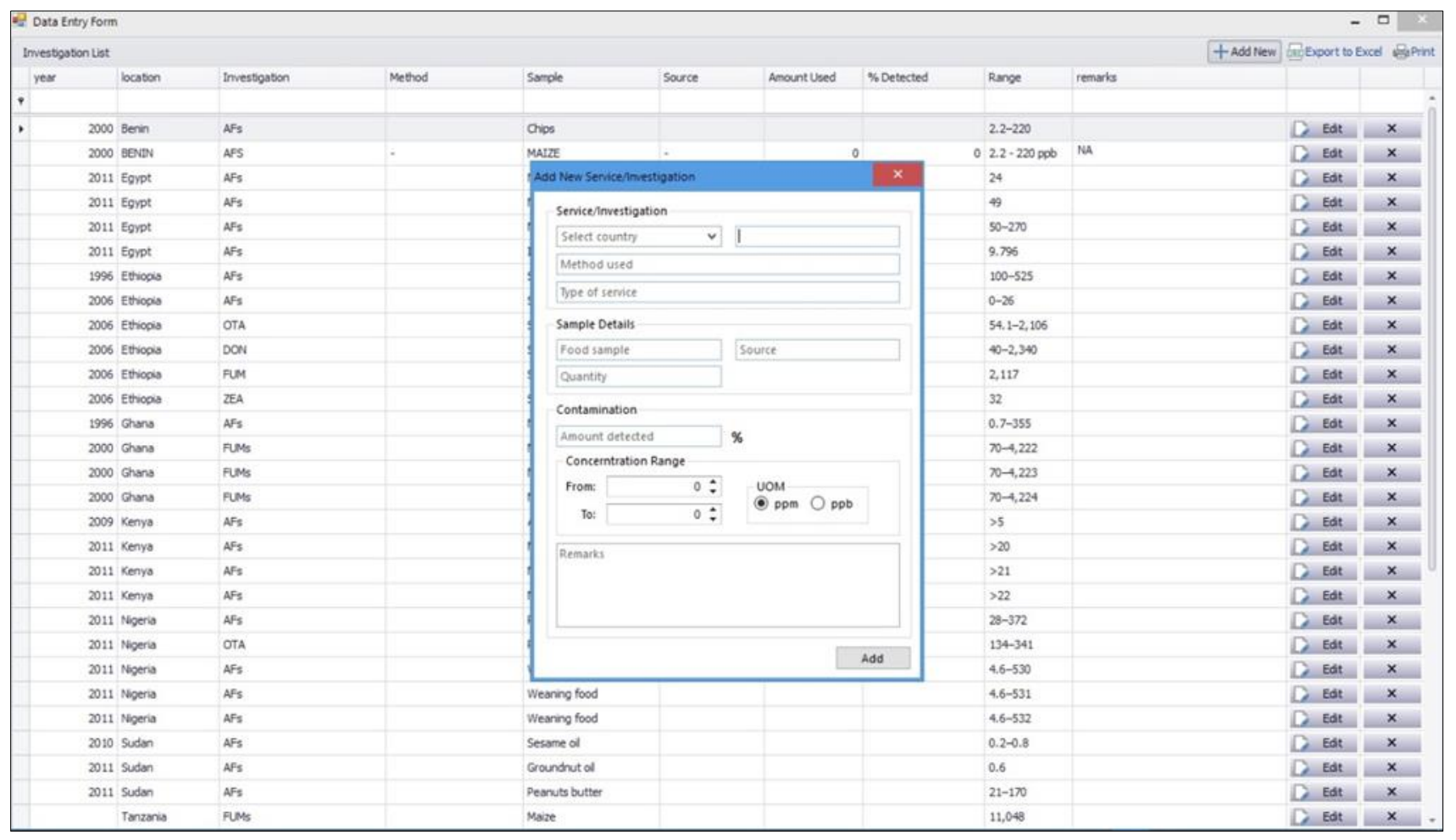

- $\quad$ Make necessary inputs

- $\quad$ click the Add button, when done

- $\quad$ Corfirm the new entry on the grid view list 
Table 7 The view of the captured data in the database

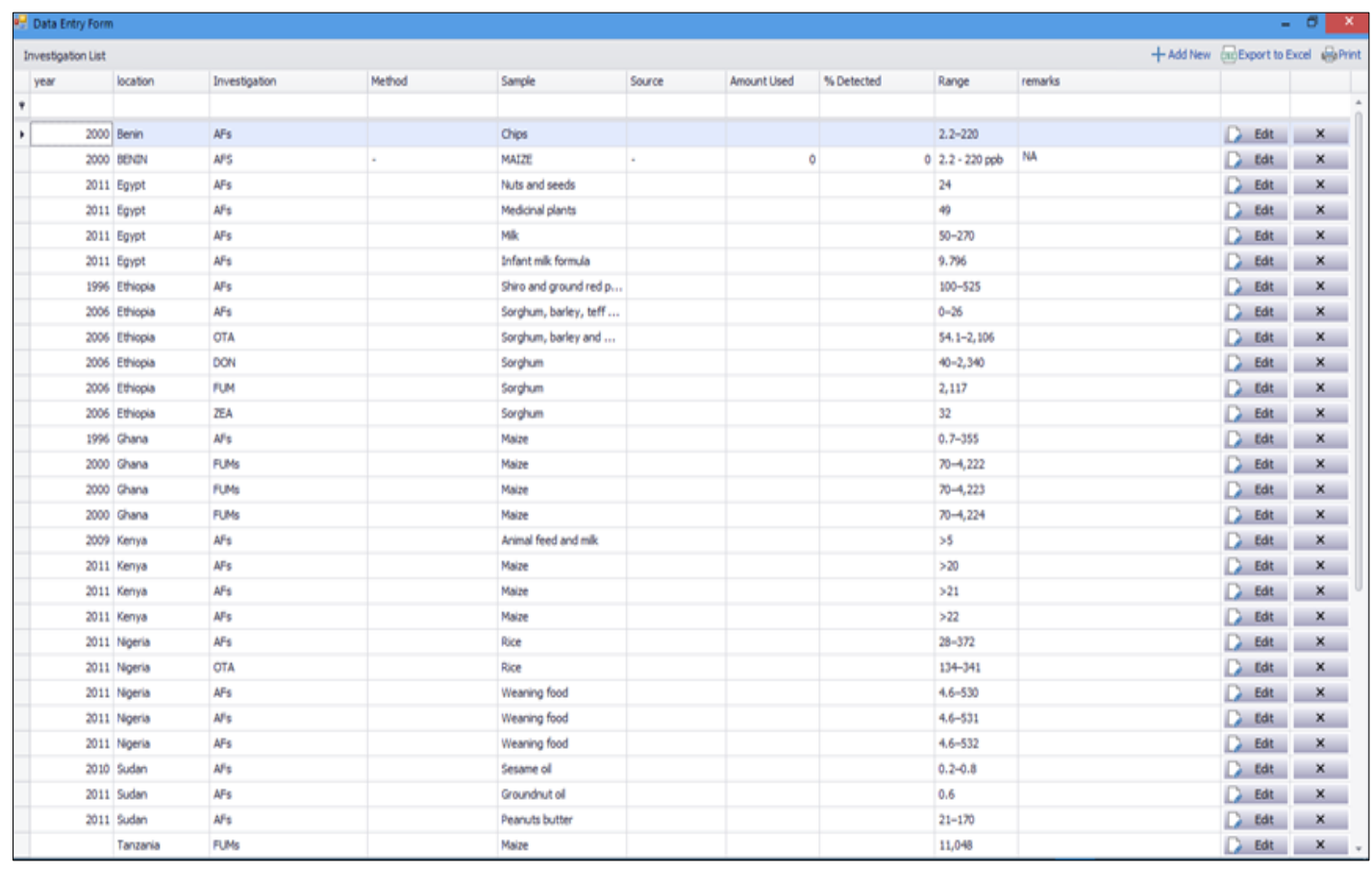

\subsection{Benefits}

The automated database system provides the client significant time and cost savings, improved its ability to analyze data, and aided decisions in the issue of mycotoxins in crops.

As a result, the solution offered the following benefits:

- $\quad$ Robust data collection, management, and analysis methods

- A secure and protected data environment

- $\quad$ Reduction in errors caused by insufficient or inconsistent data

- Data storage to facilitate regulatory compliance

- Data storage practices that offer scalability and reduced testing rework

- Improved maintainability, standardization, control, predictability, and traceability of data

- $\quad$ Enhanced decision-making capabilities in choosing better variety of crop seed and better quality end products

- $\quad$ Better audit and control procedures

- Lower costs due to automation of labor intensive tasks and elimination of redundant work

- $\quad$ Overall cost reduction due to streamlining of the traditional way of data sourcing.

- $\quad$ Reduced time-to-conclude analysis of mycotoxins in agricultural products

\section{Conclusion}

The presence of mycotoxins in grains and other staple foods and feedstuffs has serious implications for human and animal health. Many countries have enacted regulations stipulating maximum amounts of mycotoxins permissible in food and feedstuffs. Most developed countries will not permit the import of commodities containing amounts of mycotoxins above specified limits. Mycotoxins therefore have implications for trade between nations. Prevention of fungal invasion of commodities is by far the most effective method of avoiding mycotoxin problems. The role Information Technology cannot be over emphasized in this matter. For accuracy in monitoring and management of mycotoxins and its related diseases, a pool of data must be in place. Therefore, the automated database system will be of great help which will lead to a sustainable development.

\section{Recommendation}

- The Mycotoxins association should organise training programme to create awareness of the automated database system to Sub-Saharan Africa. 
- Government should fund the research of mycotoxin, for this is a necessity for life security. Since this involves crops and feedstuff, the lives of animals and humans need to be assured. This is also major case when we talk of sustainability development.

- $\quad$ The ICT centers should be made available for research officers and the farmers to ensure communication and proper interaction via the database

\section{Compliance with ethical standards}

\section{Acknowledgments}

The International University, Bamenda, (IUB) cameroon provided Research Support for this project and Dr (Evang.) Ruby Odega provided funding for participation in scientific conferences. I use this opportunity to appreciate the student on industrial training at the Information and Technology Division of the Federal Institute of Industrial Research Oshodi, Lagos, who participated in software analyses. I also wish to express my heartfelt gratitude to staff of Planning, Technology Transfer and Information Management F.I.I.R.O for providing support during the statistical analysis of experimental results and also staff of Nigerian Upstream Petroleum Regulatory Commission (NUPRC) and Chevron Nigeria Limited for providing valuable advice on some aspect of prevention of environmental pollution and enhancing sustainable development.

\section{Disclosure of conflict of interest}

There are no conflicts of interest

\section{References}

[1] S Bankole. Institute of Animal Nutrition, and university of Hehenhein, Emi-wolf-str 10,70599 stuttgart, Germany. 2006.

[2] Abarca ML, MR Bragulat, G Sastella, FJ Cabanes. Ochratoxin A production by strains of Aspergillus niger var. niger. Appl. Environ. Microbiol. 1994; 60: 2650-2652.

[3] Abramson D, E Usleber, E Marlbauer. Immunochemical method for citrinin. In M. W. Trucksess and A. F. Pohland (ed.), Mycotoxin protocols. Humana Press, Totowa, N.J. 2001; 195-204.

[4] American Academy of Pediatrics. Toxic effects of indoor molds. Pediatrics. 1998; 101: 712-714.

[5] Anderson SJ. Compositional changes in surface mycoflora during ripening of naturally fermented sausages. J. Food Protect. 1995; 58: 426-429.

[6] Barrett J. Mycotoxins: of molds and maladies. Environ. Health Perspect. 2000; 108: A20-A23.

[7] Bayman P, JL Baker, MA Doster, TJ Michailides, NE Mahoney. Ochratoxin production by the Aspergillus ochraceus group and Aspergillus alliaceus. Appl. Environ. Microbiol. 2002; 68: 2326-2329.

[8] Kahn JM, Katz RH, Pister KSJ. Next Century Challenges: Mobile Networking for "Smart Dust". Proceedings of the 5th Annual ACM/IEEE International Conference on Mobile Computing and Networking; Seattle, WA, USA. August 1999; 271-278.

[9] Akyildiz IF, Su W, Sankarasubramaniam Y, Cayirci E. Wireless sensor networks: a survey. Comput. Netw. 2002; 38: 393-422.

[10] Fukatsu T, Hirafuji M. Field monitoring using sensor-nodes with a Web server. J. Rob. Mechatron. 2005; 17: 164172.

[11] Otuka A, Sugawara K. A labor management application using handheld computers. Agric. Inf. Res. 2003; 12: 95104.

[12] Bange MP, Deutscher SA, Larsen D, Linsley D, Whiteside S. A handheld decision support system to facilitate improved insect pest management in Australian cotton systems. Comput. Electron. Agric. 2004; 43: 131-147.

[13] Yokoyama K. Promoting the Good Agricultural Practice Movement through Interactive and Seamless Communication based on User-friendly Mobile Information Technology. Proceedings of the International Seminar on Technology Development for Good Agricultural Practice in Asia and Oceania; Tsukuba, Japan. October $2005 ; 213-219$. 